\title{
ESTUDO DA EROSÃO HIDRÁULICA DO CONCRETO REFORÇADO COM FIBRAS DE AÇO
}

\author{
RAMPANELLI, CARLOS H. OLIVEIRA \\ Mestrando em Engenharia Civil \\ Universidade Federal da Integração Latino-Americana \\ Paraná; Brasil \\ carlos.rampanelli12@gmail.com
}

\section{REGINATO, LEANDRO}

Acadêmico de Engenharia Civil

Universidade Estadual do Oeste do Paraná

Paraná; Brasil

leandro_reginato@hotmail.com

\author{
GAVA, GIOVANNA PATRÍCIA \\ Professora Doutora \\ Universidade Estadual do Oeste do Paraná \\ Paraná; Brasil \\ gpgava@gmail.com
}

\author{
TRENTINI, CAMILA BORTOLOSO \\ Engenheira Civil \\ Universidade Estadual do Oeste do Paraná \\ Paraná; Brasil \\ camibtrentini@gmail.com
}

\author{
RIZZI, ROGÉRIO LUIS \\ Professor Doutor \\ Universidade Estadual do Oeste do Paraná \\ Paraná; Brasil \\ rogeriorizzi@hotmail.com
}

\section{RESUMO}

O concreto utilizado em estruturas hidráulicas está sujeito à ação da água, que ocasiona o seu desgaste superficial. Esta deterioração física pode-se manifestar por meio de três mecanismos, que são a erosão hidráulica, a abrasão hidráulica e a cavitação. Em estruturas hidráulicas, é comum a adição de fibras de aço ao concreto, no qual as fibras têm a função de melhorar a resistência à tração e a tenacidade. Em consequência disso, este reforço fibras de aço também promove o aumento da resistência à abrasão hidráulica do concreto, contudo, é desconhecido o efeito das fibras na resistência à erosão hidráulica. Este trabalho verificou a influência da adição de diferentes teores - 0, 40, 60 e $80 \mathrm{~kg} / \mathrm{m}^{3}$ - do mesmo tipo de fibra de aço no concreto frente à erosão hidráulica. Utilizou-se para o desenvolvimento do trabalho, um ensaio não normatizado de erosão hidráulica que consiste na incidência de um jato de água de alta velocidade diretamente sobre a superfície do corpo de prova, sendo analisada sua perda de massa ao longo de 120 minutos de ensaio. Ademais, foi realizado ajuste de modelo matemático aos dados experimentais, constatando seu bom desempenho na descrição do desgaste hidroerosivo. Não foi verificada influência significativa da fibra de aço no aumento da resistência erosiva dos concretos, contudo a presença da fibra de aço não aumentou a perda de massa por erosão hidráulica.

Palavras-chave: ensaio hidroerosivo, reforço estrutural descontínuo, desgaste do concreto.

\begin{abstract}
The concrete utilized in hydraulic structures is subject to water action, which produces its surface wear. This physical deterioration may manifest itself by means of three mechanisms, which are the hydraulic erosion, hydraulic abrasion and cavitation. In hydraulic structures, the addition of steel fibers to the concrete is common, in which the fibers have the function of improving tensile strength and toughness. As a result, this steel fiber reinforcement also promotes increased hydraulic abrasion strength of the concrete, however the effect of the fibers on the strength to hydraulic erosion is unknown. Thus, this work aims to verify the influence of the addition of different contents - $0,40,60 \mathrm{and} 80 \mathrm{~kg} / \mathrm{m}^{3}-\mathrm{of}$ the same type of steel fiber in the concrete in front of the hydraulic erosion. A non-standard hydraulic erosion test consisting of the incidence of a high-velocity water jet directly on the surface of the test specimen was used for the development of the work and the mass loss observed was analyzed over a 120 minutes test. In addition, a mathematical model was adjusted to the experimental data, noting its good performance in the description of hydro erosive wear. Regarding the performance of the CRFA with different fiber additions, no significant influence of the steel fiber on the erosive strength of the concretes was verified, however the presence of that did not increase in the mass loss due to hydraulic erosion.
\end{abstract}

Keywords: hydroerosive test, discontinuous structural reinforcement, concrete wear. 


\section{INTRODUÇÃO}

O concreto é um material amplamente utilizado na construção civil devido à sua boa resistência ao esforço de compressão, facilidade de manejo, aplicação e durabilidade. No entanto, é um material frágil, que apresenta baixa resistência à tração e baixa capacidade à deformação. A adição de fibras é empregada com o intuito de melhorar tais características, sendo que estas apresentam boa resistência à tração, maior ductilidade e tenacidade, entre outros aspectos (MINDESS, $1994 \mathrm{e}$ FIGUEIREDO, 2011).

A utilização de fibras nos materiais de construção data desde o Egito Antigo, citado em Êxodo, em que utilizava-se de palha para confecção de tijolos de barro (MEHTA; MONTEIRO, 2008). As fibras foram aprimoradas e são adicionadas como reforço para concretos na construção civil.

Essa adição é benéfica à matriz cimentícia. Fibras com adequada resistência à tração e distribuídas de forma homogênea no concreto, constituem uma micro armadura que, mostra-se eficaz para combater o fenômeno da fissuração por retração, além de conferir considerável ductilidade ao material que foi adicionado à medida em que se elevam sua quantidade e resistência (SARZALEJO et al, 2010).

Segundo Naaman (2000), as fibras podem ser classificadas conforme seu material, suas propriedades físicas e químicas e suas propriedades mecânicas. As fibras metálicas, e especialmente as de aço, são as mais empregadas no reforço de concretos e argamassas por serem mais eficazes e relativamente econômicas (CANOVAS, 1997). O concreto acrescido de fibras artificiais de aço é nomeado de Concreto Reforçado com Fibras de Aço (CRFA).

O CRFA é utilizado como solução para execução de barragens de contenção de água com geração ou não de energia. Cita-se como exemplo o Vertedouro Extravasor de Troncos (VET) da Usina Hidrelétrica Santo Antônio, situada em Rondônia, e a construção de partes do vertedouro da Usina Hidrelétrica de Itaipu. Segundo Chieregato et al. (2016), o uso do CRFA na construção do VET da usina Santo Antônio dispensou o uso de mais de 5000 metros de perfis metálicos, além de oportunizar o controle dos riscos de fissuração do concreto.

A utilização de CRFA é recorrente, inclusive, em estruturas marítimas, hidráulicas, revestimento de tubulações e paredes de canais, onde o concreto está sujeito ao ataque da água. A ação da água provoca desgaste na superfície do concreto que compromete sua durabilidade, resistência e outros atributos físicos no estado endurecido, tornando o desgaste hidráulico um problema (MOMBER; KOVACEVIC, 1994).

\subsection{Erosão hidráulica}

O desgaste físico hidráulico pode ser definido como a perda de massa de um material por fricção ou atrito quando submetido à ação da água. Conforme Momber et al. (1995) este pode ser dividido em três tipos, sendo por erosão, por cavitação e por abrasão. A erosão trata da ação direta do fluxo de água em alta velocidade, que é o enfoque deste trabalho. Já a cavitação está relacionada à ação de bolhas de gases geradas por meio da redução da pressão em escoamentos turbulentos. A abrasão diz respeito à ação de partículas sólidas suspensas no fluído que, ao colidirem no concreto em alta velocidade, desgastam a superfície do material.

Mecanicamente o CRFA vem a mitigar uma lacuna do concreto comum, que como apontado por Figueiredo (2005), é a associação da baixa capacidade de resistência à tração do concreto à sua grande dificuldade de interromper a propagação de fissuras quando é submetido a este tipo de esforço. Nessa situação, o papel das fibras é um mecanismo relevante em restringir à propagação de fissuras devido ao trabalho como ponte de transferência de tensão através das fissuras do concreto. Como o processo erosivo consiste em um evento de geração e propagação de fissuras sucessivas como apontado por Momber e Kovacevic (1994), é pertinente o estudo do CRFA para mitigar o desgaste provocado pela erosão hidráulica.

Motivados a melhor entender o desgaste do concreto em estruturas hidráulicas, Momber e Kovacevic (1994) e Momber et al (1995), desenvolveram o ensaio de erosão hidráulica para simular o efeito da incidência do fluxo de água em alta velocidade sobre a superfície de um material. Eles verificaram que para a ocorrência de danos visíveis no material é necessário uma velocidade crítica do fluxo de água e um tempo crítico de exposição. Tal ensaio corresponde à aplicação de um jato de água em alta velocidade sobre a superfície de um corpo de prova durante um determinado tempo.

Horszczaruk (2008) aplicou um modelo matemático desenvolvido por Sitnik (2008) à quantificação da perda de massa por processos abrasivo-erosivos. Tal modelo, designado neste trabalho, como Sitnik-Horszczaruk, é fundamentado na 
Teoria de Confiabilidade e é apropriado para quantificar a perda de massa de diferentes materiais, incluindo o concreto reforçado com fibras de aço que foi o material utilizado nos ensaios realizados em laboratório. Conceitualmente, o modelo para a mensuração de massa removida pela interação de partículas sólidas ou líquida com a superfície do material é determinado por meio da Equação (1)

$$
m(t)=a\left[\ln (t+1)^{b}\right]
$$

em que $a$ e $b$ são parâmetros de ajuste aos dados (adimensional), $t$ é o tempo em que a carga hidráulica realiza o desgaste (min) e $m(t)$ é a massa média acumulada das partículas extraídas até ao tempo final do ensaio (g).

Embora ensaio erosivo seja relevante à compreensão do efeito erosivo em superfícies de concreto, existem poucos estudos acerca do desgaste erosivo, menos ainda em relação ao desempenho do Concreto Reforçado com Fibras de Aço frente à erosão hidráulica. Levando isso em consideração, neste trabalho foi verificada a influência da adição e teor de fibras de aço na resistência à erosão hidráulica do concreto.

\section{MATERIAIS E MÉTODOS}

Com o intuito de averiguar a influência da adição das fibras de aço ao concreto frente à erosão hidráulica, foi desenvolvido o programa experimental que será apresentado nesta seção. Vale ressaltar que os concretos testados neste trabalho são os mesmos ensaiados à abrasão por Grolli (2017). Sendo assim, os corpos de prova de CRFA, que neste trabalho foram ensaiados à erosão, foram moldados juntamente com os de Grolli (2017) e, portanto, a metodologia e as características dos materiais empregados são comuns em ambos os trabalhos.

\subsection{Agregados}

A caracterização dos agregados foi realizada no Laboratório de Estruturas e Materiais de Engenharia (LEME) da Universidade Estadual do Oeste do Paraná (UNIOESTE), por meio dos seguintes ensaios:

a) Teor de material pulverulento (ABNT NBR NM 46, 2009);

b) Composição granulométrica (ABNT NBR NM 248, 2009);

c) Massa específica aparente do agregado miúdo (ABNT NBR NM 52, 2003);

d) Massa específica aparente do agregado graúdo (ABNT NBR NM 53, 2003).

Foram utilizados areia natural e pedrisco como agregados na composição do concreto, e estes apresentaram teor de material pulverulento abaixo do limite estabelecido na ABNT NBR 7211 (2009), sendo que a areia não se enquadrou na zona utilizável e o pedrisco pode ser classificado como agregado total (ABNT NBR 7211, 2009). As principais características destes agregados constam na Tabela 1.

Tabela 1 - Características dos agregados utilizados (GROLLI, 2017)

\begin{tabular}{c|c|c} 
Características & Areia Natural & Pedrisco \\
\hline Dimensão Máxima Característica $(\mathrm{mm})$ & 0,60 & 9,50 \\
\hline Dimensão Mínima Característica $(\mathrm{mm})$ & 0,15 & 1,18 \\
\hline Módulo de Finura & 1,39 & 5,45 \\
\hline Teor de Material Pulverulento $(\%)$ & 0,38 & 2,32 \\
\hline Massa Unitária $\left(\mathrm{kg} / \mathrm{dm}^{3}\right)$ & 1,51 & 1,59 \\
\hline Massa Específica Aparente Seca $\left(\mathrm{kg} / \mathrm{dm}^{3}\right)$ & 2,65 & 2,90 \\
\hline
\end{tabular}

\subsection{Cimento}

Para as moldagens foi utilizado o Cimento Portland Composto com Fíler da Votorantim Cimentos, CP II-F-40. A caracterização do aglomerante de acordo com seus índices químicos, físicos e mecânicos, consta nas tabelas 2, 3, 4, respectivamente, e foram obtidos junto ao fabricante. 


\section{СВРAT 2020 \\ CONGRESSO BRASILEIRO DE PATOLOGIA DAS CONSTRUÇÕES \\ DE 15 A 17 DE ABRIL | FORTALEZA - CE}

Tabela 2 - Caracterização do cimento CP II-F-40 conforme seus índices químicos

(VOTORANTIM CIMENTOS, 2017)

\begin{tabular}{c|c|c|c|c}
\hline Teores (\%) & Perda ao fogo & $\mathrm{MgO}$ & $\mathrm{SO}_{3}$ & Resíduo Insolúvel \\
\hline Limites da Norma & $\leq 6,50$ & $\leq 6,50$ & $\leq 4,00$ & $\leq 2,50$ \\
\hline Média & 5,18 & 6,30 & 3,51 & 1,18 \\
\hline Desvio Padrão & 0,26 & 0,16 & 0,13 & 0,18 \\
\hline Mínimo & 4,74 & 5,69 & 3,33 & 1,00 \\
\hline Máximo & 5,93 & 6,28 & 3,85 & 1,86 \\
\hline
\end{tabular}

Tabela 3 - Caracterização do cimento CP II-F-40 conforme seus índices físicos

\begin{tabular}{|c|c|c|c|c|c|c|c|}
\hline \multirow{3}{*}{ Índices Físicos } & \multicolumn{6}{|c|}{ OTORANTIM CIMENTOS, 2017) } & \multirow{3}{*}{$\begin{array}{c}\text { Expansibilidade } \\
\text { a quente (mm) }\end{array}$} \\
\hline & \multicolumn{2}{|c|}{ Finura $(\%)$} & \multirow{2}{*}{$\begin{array}{l}\text { Blaine } \\
(\mathrm{cm} 2 / \mathrm{g})\end{array}$} & \multirow{2}{*}{$\begin{array}{c}\text { Água de consist. } \\
(\%)\end{array}$} & \multicolumn{2}{|c|}{ Tempo de Pega } & \\
\hline & $\# 200$ & \#325 & & & Início (min) & Fim (min) & \\
\hline Limites da Norma & $\leq 10,0$ & N/A & $\geq 2800$ & N/A & $\leq 60$ & $\geq 60$ & $\leq 5,0$ \\
\hline Média & 0,00 & 0,10 & 4416,82 & 29,94 & 212,27 & 273,18 & 0,34 \\
\hline Desvio Padrão & 0,00 & 0,13 & 103,94 & 0,87 & 15,87 & 19,61 & 0,32 \\
\hline Mínimo & 0,00 & 0,00 & 4220,00 & 26,40 & 180,00 & 240,00 & 0,00 \\
\hline Máximo & 0,00 & 0,30 & 4700,00 & 30,60 & 245,00 & 310,00 & 1,00 \\
\hline
\end{tabular}

Tabela 4 - Caracterização do cimento CP II-F-40 conforme sua resistência à compressão (VOTORANTIM CIMENTOS, 2017)

\begin{tabular}{c|c|c|c|c}
\hline \multirow{2}{*}{ Resistência à Compressão $(\mathrm{MPa})$} & \multicolumn{4}{|c}{ Tempo } \\
\cline { 2 - 5 } & 1 dia & 3 dias & 7 dias & 28 dias \\
\hline Limites da Norma & N/A & $\geq 15,00$ & $\geq 25,00$ & $\geq 40,00$ \\
\hline Média & 25,52 & 36,07 & 42,01 & 49,23 \\
\hline Desvio Padrão & 0,87 & 1,22 & 0,95 & 0,95 \\
\hline Mínimo & 24,00 & 33,50 & 40,30 & 47,20 \\
\hline Máximo & 27,40 & 37,80 & 43,70 & 51,00 \\
\hline
\end{tabular}

\subsection{Aditivo}

Utilizou-se nas moldagens o aditivo MC-PowerFlow 1180 da MC-Bauchemie, um superplastificante polimérico de alto desempenho. Suas especificações técnicas estão resumidas na Tabela 5.

Tabela 5 - Especificações técnicas do aditivo Superplastificante MC-PowerFlow 1180

\begin{tabular}{c|c}
\multicolumn{2}{c}{ (MC-BAUCHEMIE, 2017) } \\
\hline Características & Valor \\
\hline Densidade $(\mathrm{g} / \mathrm{m} 3)$ & 1,09 \\
\hline Dosagem recomendada $(\%)$ & 0,20 a 5,00 \\
\hline Teor de cloretos $(\%)$ & $<0,10$ \\
\hline Teor de Álcalis $(\%)$ & $<1,00$ \\
\hline Cor & Marrom \\
\hline Estado & Líquido
\end{tabular}

\subsection{Definições das variáveis e do concreto avaliado}

Foi empregada a fibra de aço do tipo RC 65/35 BN da marca Dramix, que apresenta um fator de forma, $\lambda$, de 64 , e cujas demais informações técnicas estão dispostas na Figura 1. Os teores testados foram de 0, 40,60 e $80 \mathrm{~kg}$ de massa de fibra 
por $\mathrm{m}^{3}$ de concreto, em que foi mantida a proporção do concreto constante, a fim de avaliar a influência da quantidade de fibras na resistência à erosão hidráulica. A metodologia utilizada na definição dos teores e tipo de fibra, bem como o proporcionamento do concreto utilizado foi estabelecida por Grolli (2017).

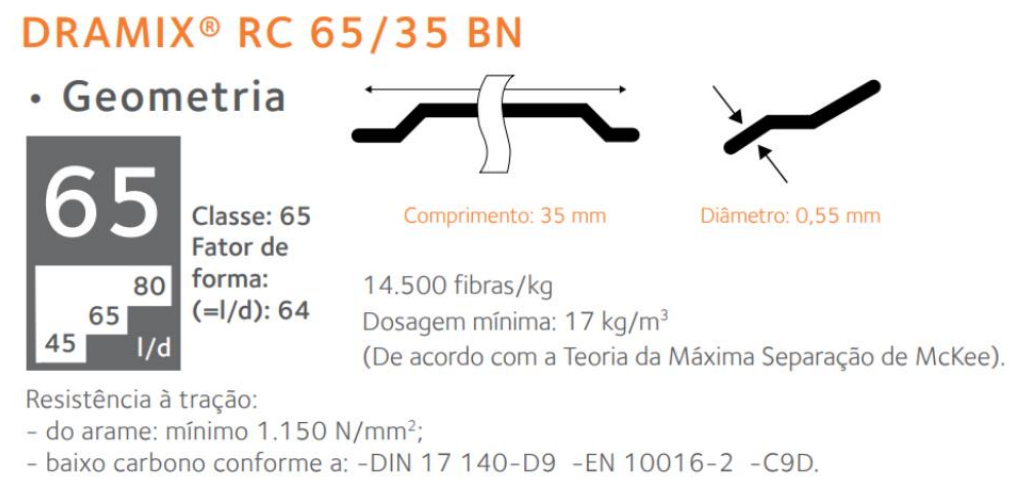

Figura 1: Informações técnicas da fibra de aço Dramix RC 65/35 BN (Catálogo Dramix)

A proporção do concreto escolhida para avaliar o comportamento do concreto com reforço de fibras de aço foi o de Gava (2006) e é apresentado na Tabela 6. Em que, $m$ é o teor total de agregados, $\alpha$ é o teor de argamassa e $H$ é a relação água/materiais secos.

Tabela 6 - Proporção dos materiais e parâmetros do concreto reforçado com fibras de aço utilizado

\begin{tabular}{c|c|c|c|c|c|c|c|c}
\hline Cimento & Areia & Pedrisco & Água/cimento & $m$ & $\begin{array}{c}\alpha \\
(\%)\end{array}$ & $\begin{array}{c}H \\
(\%)\end{array}$ & $\begin{array}{c}\text { Consumo de fibras } \\
\left(\mathrm{kg} / \mathrm{m}^{3}\right)\end{array}$ & $\begin{array}{c}\text { Teor de aditivo } \\
(\%)\end{array}$ \\
\hline 1 & 2,04 & 1,67 & 0,44 & 3,71 & 65 & 9,34 & $0,40,60$ e 80 & 0,33 \\
\hline
\end{tabular}

\subsection{Confecção dos corpos de prova}

A moldagem de corpos de prova de CRFA contemplou àqueles utilizados para ensaio de abrasão hidráulica estudada por Grolli (2017), e os utilizados para ensaio de erosão hidráulica, tema deste trabalho. Dessa forma, foram produzidos os seguintes corpos de prova para cada teor de fibra avaliado:

a) Uma placa de concrto quadrada de $42 \mathrm{~cm}$ de largura e $3 \mathrm{~cm}$ de altura, empregando o molde metálico da Figura 2a. Do corte dessa placa foram obtidos corpos de prova de $8 \mathrm{~cm}$ de largura e $3 \mathrm{~cm}$ de altura (Figura 2b). Destes foram utilizados ao menos três corpos de prova para realização de ensaios de desgaste superficial por erosão hidráulica para cada teor de fibra.

b) Doze corpos de prova cilíndricos de $10 \mathrm{~cm}$ de diâmetro e $20 \mathrm{~cm}$ de altura para os ensaios de compressão axial (ABNT NBR 5739, 2007) e módulo de elasticidade (ABNT NBR 8522, 2004).

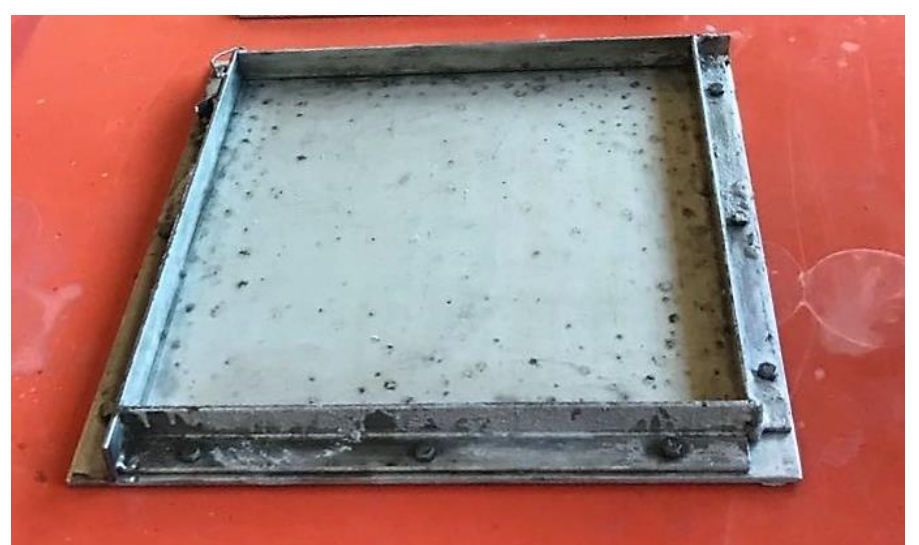

(a)

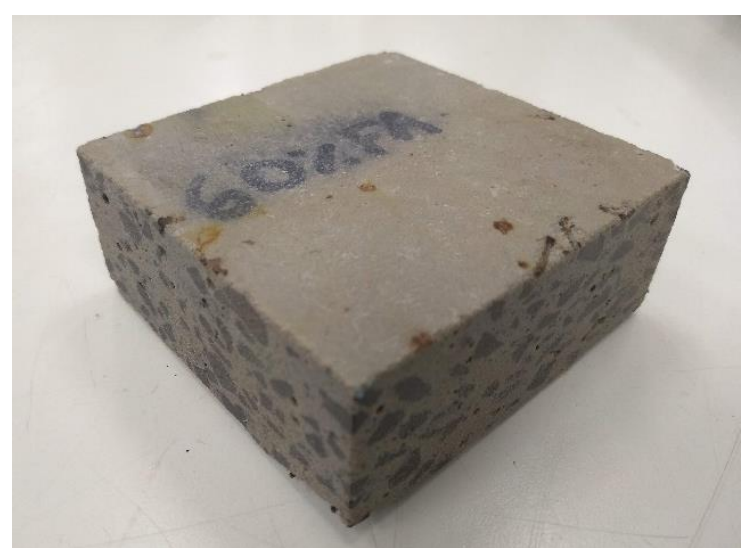

(b)

Figura 2: (a) Placa utilizada nas moldagens. (b) Corpo de prova utilizado nos ensaios hidroerosivos 
Para todos os teores de fibra manteve-se constante o consumo de aditivo de 0,33\% do consumo do cimento, com uma certa variação no abatimento das misturas de concreto. No entanto, notou-se que os concretos com maior consumo de fibras apresentaram menor trabalhabilidade, que foi caracterizada pela maior dificuldade em seu lançamento e acabamento superficial. O consumo de aditivo utilizado frente ao abatimento de tronco de cone (NBR NM 67,1998) obtido são apresentados na Tabela 7.

Tabela 7 - Consumo de aditivo superplastificante e abatimento por tronco de cone dos concretos avaliados

(GROLLI, 2017)

\begin{tabular}{c|c|c|c}
\hline Concreto & $\begin{array}{c}\text { Consumo de aditivo } \\
(\%)\end{array}$ & Abatimento sem fibras (mm) & Abatimento com fibras (mm) \\
\hline 0FA & 0,33 & 120 & - \\
\hline 40FA & 0,33 & 50 & 90 \\
\hline 60FA & 0,33 & 80 & 60 \\
\hline 80FA & 0,33 & 85 & 80 \\
\hline
\end{tabular}

Por meio da determinação da massa específica do concreto no estado fresco, foi possível estimar o teor de ar incorporado. Notou-se que o aumento do teor de fibras resultou em um menor teor de ar incorporado, ou seja, uma diminuição da porosidade do concreto, característica já mencionada por fabricantes de fibras de aço. A Tabela 8 apresenta estes resultados.

Tabela 8 -Massa específica dos concretos no estado fresco e o percentual de vazios de ar (GROLLI, 2017)

\begin{tabular}{c|c|c} 
Concreto & $\begin{array}{c}\text { Massa específica no estado fresco } \\
\left(\mathrm{kg} / \mathrm{m}^{3}\right)\end{array}$ & Vazios de ar (\%) \\
\hline 0FA & 2334 & 5,79 \\
\hline 40FA & 2393 & 2,93 \\
\hline 60FA & 2400 & 2,41 \\
\hline 80FA & 2455 & 0,00 \\
\hline
\end{tabular}

Conforme Grolli (2017) o percentual de vazios ou teor de ar incorporado do concreto 0FA é alto, já que está acima de $4 \%$, enquanto que o concreto 80FA não apresentou vazios.

O concreto foi adensado em mesa vibratória, com tempo de vibração de 10 segundos. Na Figura 3 pode-se observar a placa base de concreto após o adensamento por vibração.
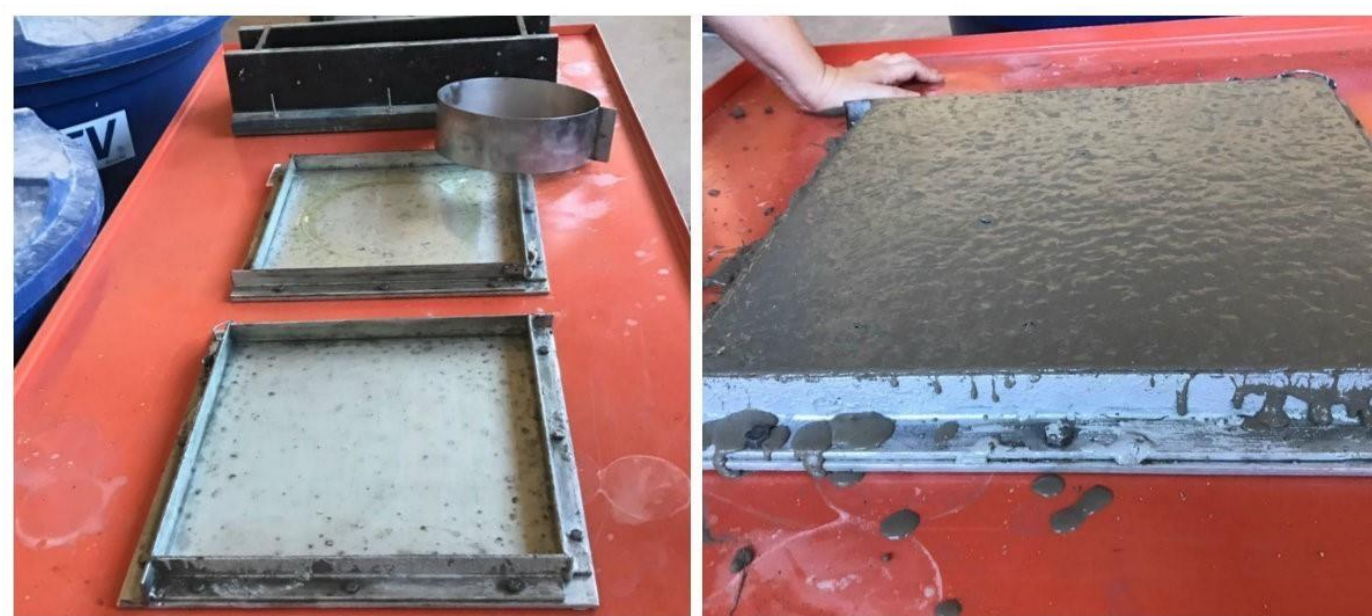

Figura 3 - Placas base durante o adensamento do concreto na mesa vibratória (GROLLI, 2017)

Após 24 horas da moldagem, os corpos de prova foram desmoldados e submetidos à cura com água e cal hidratada, conforme a ABNT NBR 5738 (2003). Os corpos de prova cilíndricos 10×20 cm, necessitaram de regularização de sua superfície por meio de capeamento com enxofre, já que a presença de fibras poderia danificar o disco da fresa. Assim, 
estes foram ensaiados à compressão nas idades de 1, 7 e 72 dias, enquanto que o módulo de elasticidade foi determinado somente nesta última idade. Os resultados de caracterização do concreto quanto aos parâmetros mecânicos citados estão apresentados na Tabela 9 .

Tabela 9 - Resultados de resistência à compressão, em função da idade, e módulo de elasticidade dos concretos (GROLLI, 2017)

\begin{tabular}{c|c|c|c|c|c}
\hline \multirow{2}{*}{ Concreto } & \multicolumn{3}{|c|}{ Resistência à Compressão $(\mathrm{MPa})$} & \multicolumn{2}{c}{ Módulo de Elasticidade (GPa) } \\
\cline { 5 - 6 } & \multicolumn{2}{|l}{} & Experimental & Teórico \\
\hline Idade & 1 dia & 7 dias & 72 dias & 72 dias & 72 dias \\
\hline 0FA & 19,00 & 42,70 & 51,30 & 37,90 & 40,10 \\
\hline 40FA & 26,90 & 42,00 & 54,80 & 36,80 & 41,40 \\
\hline 60FA & 29,90 & 46,91 & 55,32 & 38,63 & 41,63 \\
\hline 80FA & 30,80 & 44,60 & 55,40 & 39,80 & 41,70 \\
\hline
\end{tabular}

Observa-se na Tabela 9 que o teor de fibras de aço não provocou alteração considerável na resistência à compressão dos concretos avaliados. A resistência à compressão do concreto sem adição de fibras foi inferior aos demais, para a idade de 1 dia, que é explicado pela temperatura baixa no dia de sua moldagem, ocasionando retardo da pega. Nas demais idades este fenômeno não apresentou interferência (GROLLI, 2017).

Quanto aos resultados de módulo de elasticidade, estes variaram pouco entre si. Grolli (2017) ainda utilizou a equação da ABNT NBR 6118 (2014) para estimar o módulo de elasticidade por meio da resistência à compressão, que superestimou o valor obtido. Este resultado é explicado por Gava (2006), que afirma que a fórmula foi desenvolvida para concretos convencionais com teor de argamassa com cerca de 52\%, enquanto que os concretos moldados apresentavam teor de argamassa de $65 \%$.

\subsection{Realização do ensaio de erosão hidráulica}

O ensaio de erosão hidráulica tem sua metodologia adaptada dos estudos de Momber e Kovacevic (1994) e Momber et al (1995). Com inspiração nesta metodologia, foi construído um aparato de erosão por hidrojateamento (Figura 4), para realização do ensaio de erosão hidráulica que consiste em submeter os corpos de prova de $8 \times 8 \times 3 \mathrm{~cm}$, moldados com CRFA, à incidência do jato de água em um tempo de 120 min de ensaio. Durante o ensaio são realizadas medições da perda de massa ao longo deste tempo por meio de balança de precisão de três casas decimais, 0,001 g.

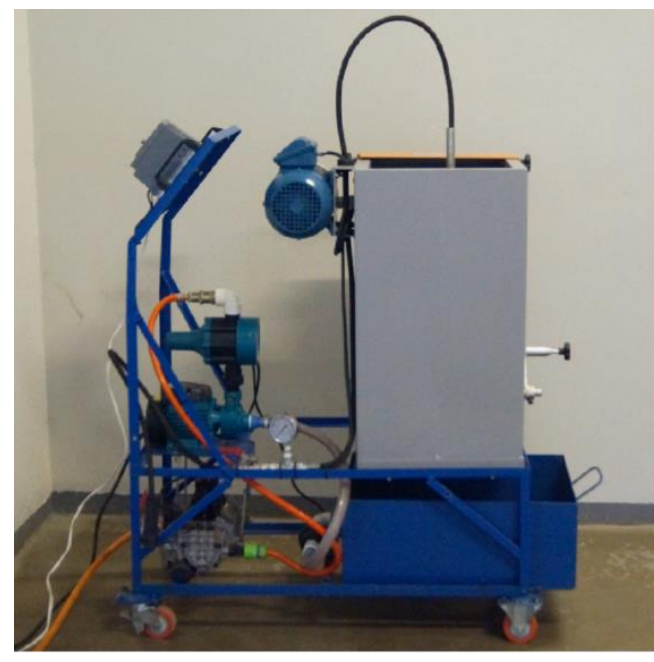

Aparato experimental

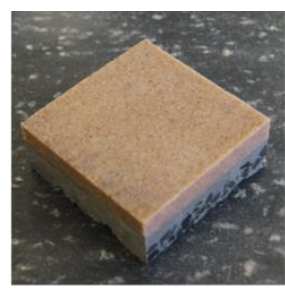

Amostra antes do teste

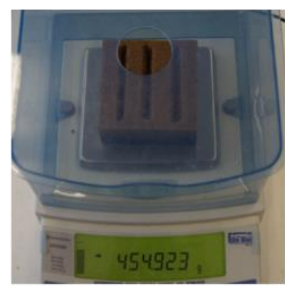

Pesagem da amostra

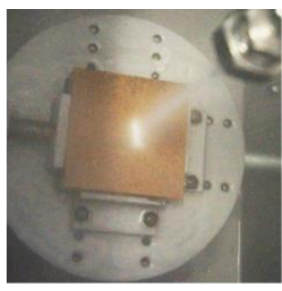

Teste em andamento

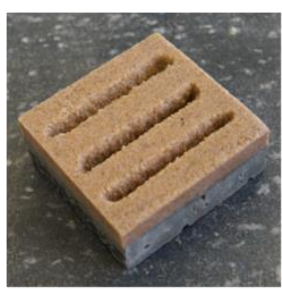

Amostra desgastada

Figura 4: Aparato de erosão hidráulica e algumas fases do ensaio erosivo (RAMPANELLI et al, 2018)

Antes do início do teste, foi realizada a medição da massa inicial do corpo de prova saturado e superficialmente seco. Posteriormente, aplicou-se o hidrojateamento no concreto com pausas para medições de massa em intervalos de 10 
minutos, sendo que nos primeiros 5 minutos de ensaio a mensuração é foi de 1 em 1 minuto com o propósito de melhor adequação do modelo matemático aos dados, ou seja, um refinamento da curva nos primeiros minutos. A linha do tempo com os intervalos das medições é ilustrada na Figura 5.

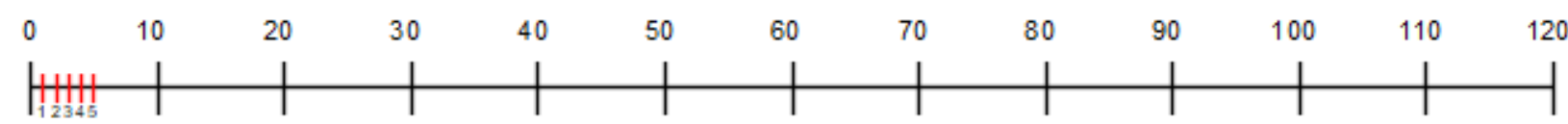

Figura 5: Linha do tempo do ensaio, em minutos, em que são indicados os intervalos de medições

Durante o ensaio, a pressão do equipamento foi mantida em 100 bar para todos os experimentos. Isto foi feito por meio do registro de regulagem de pressão. Esta regulagem objetiva a manutenção da velocidade, para que ela fique constante do início ao fim do ensaio. Além disso, o ângulo de incidência do jato de água em alta velocidade foi mantido à $90^{\circ}$ com a superfície do corpo de prova.

Devido ao movimento transversal do jato d'água em relação ao corpo de prova, a carga erosiva a qual este é submetido gera um desgaste erosivo num comprimento aproximado de 70 mm, como é mostrado na Figura 6.

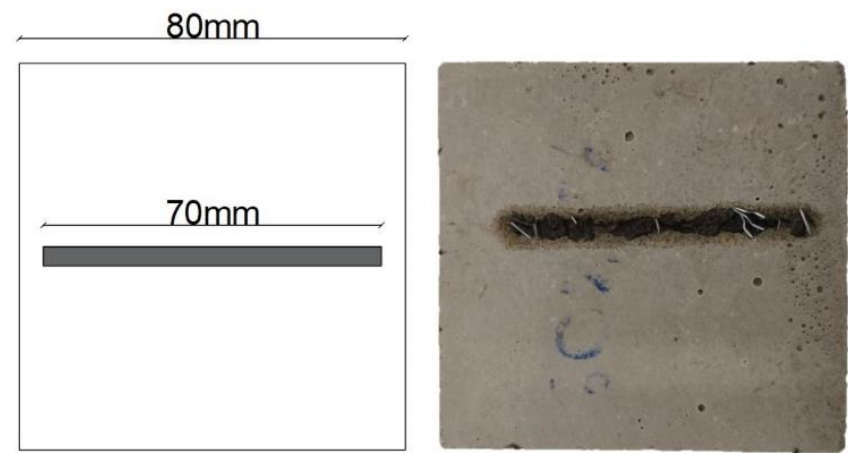

Figura 6: Representação da amplitude do desgaste erosivo

O desgaste erosivo do concreto foi avaliado por meio da perda de massa do corpo de prova ao longo dos 120 min de ensaio. A obtenção dos dados foi realizada em triplicata, ou seja, foram ensaiados três corpos de prova por teor de fibra de aço, a fim de aumentar a confiabilidade dos resultados. Para a triplicata de cada teor de fibra de aço é calculado um valor médio de perda de massa para cada intervalo de tempo. Sendo assim, ao todo foram avaliados doze corpos de prova, correspondentes às quatro triplicatas.

O modelo matemático de Sitnik-Horszczaruk foi ajustados aos dados de experimentais por meio do software STATISTICA 10 (STATSOFT, 2011). Além disso, utilizou-se do método Kolmogorov-Smirnov a fim de verificar a normalidade dos dados e, sendo esta comprovada, pode-se verificar a variância dos dados de perda de massa com o teste ANOVA.

\section{RESULTADOS}

A partir da metodologia apresentada, realizaram-se os ensaios hidroerosivos nos corpos de prova moldados com os teores de adição de 0FA, 40FA, 60FA e 80FA. O registro fotográfico dos desgastes aos 120 minutos de ensaio para cada concreto estão apresentados na Figura 7, e seus respectivos resultados finais de perda de massa acumulada estão dispostos na Tabela 10 .

Tabela 10 - Perda de massa acumulada ao final do ensaio

\begin{tabular}{c|c|c|c|c}
\hline Ensaios & OFA & 40FA & 60FA & $80 \mathrm{FA}$ \\
\hline I & 2,519 & 2,461 & 2,291 & 2,330 \\
\hline II & 1,993 & 2,026 & 2,162 & 2,224 \\
\hline III & 2,319 & 2,115 & 2,054 & 2,211 \\
\hline Média & $\mathbf{2 , 2 7 7}$ & $\mathbf{2 , 2 0 1}$ & $\mathbf{2 , 1 6 9}$ & $\mathbf{2 , 2 5 5}$ \\
\hline
\end{tabular}



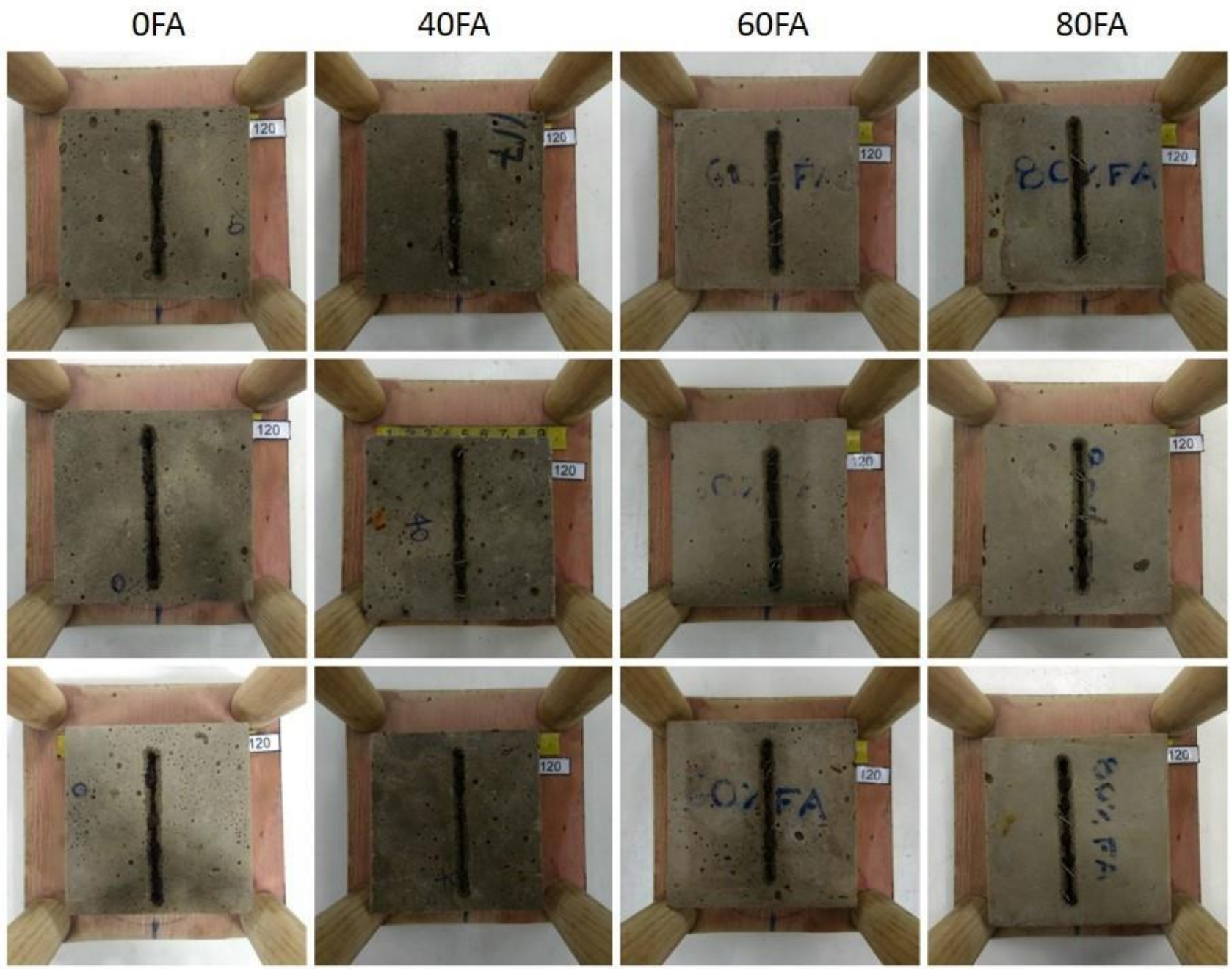

Figura 7: Representação da amplitude do desgaste erosivo

Os dados de perda de massa obtidos por meio dos ensaios hidroerosivos foram analisados estatisticamente com o objetivo de averiguar a influência da adição da fibra de aço na resistência erosiva do concreto. A análise de variância dos resultados de perda de massa pode ser conferido na Tabela 11.

\begin{tabular}{c|c|c|c|c|c}
\multicolumn{7}{c}{ Tabela 11-ANOVA } \\
\hline & $G L$ & $S Q$ & $Q M$ & $F$ & $p$-valor \\
\hline Tratamento & 3 & 0,02199 & 0,00733 & 0,20704 & 0,11128 \\
\hline Resíduo & 8 & 0,28329 & 0,03541 & & \\
\hline Total & 11 & 0,30528 & & & \\
\hline
\end{tabular}

A Tabela 11 apresenta o resultado do teste de ANOVA, em que $S Q$ é a soma dos quadrados, $G L$ são os graus de liberdade e $Q M$ é o quadrado médio. $O$ valor de $F$ calculado foi de 0,207 , enquanto que o valor crítico tabelado, $F_{t a b}$, para um nível de significância de $5 \%$ e um número de 12 amostras foi de 4,07 . Sendo assim, como $F<F_{t a b}$, considera-se que não houve significância entre as perdas de massa dos diferentes teores de fibra, ou seja, as fibras não influenciam na resistência à erosão do concreto.

Os parâmetros de ajuste do modelo matemático de Sitnik-Horszczaruk (2008) foram ajustados aos dados de perda de massa no tempo. Tais parâmetros, $a$ e $b$, estão dispostos na Tabela 12, bem como o coeficiente de determinação, $R^{2}$, da equação ajustada. 
Tabela 12 - Valores dos parâmetros ajustados aos dados de perda de massa

\begin{tabular}{c|c|c|c|c}
\hline Parâmetros & 0FA & 40FA & 60FA & 80FA \\
\hline$a$ & 0,24044 & 0,16926 & 0,32752 & 0,30221 \\
\hline$b$ & 1,40271 & 1,61649 & 1,17354 & 1,26153 \\
\hline$R^{2}$ & 0,99096 & 0,99683 & 0,99460 & 0,99722 \\
\hline
\end{tabular}

Da Tabela 12, nota-se um excelente ajuste do modelo aos dados, indicando que ele é adequado para descrever a curva de perda de massa observada, visto que o coeficiente de determinação, $R^{2}$, foi próximo a 1 . Na Figura 8 observa-se as curvas originadas do ajuste do modelo com os dados experimentais dos teores 0FA, 40FA, 60FA e 80FA, representadas nas cores verde, azul, vermelho e magenta, respectivamente.

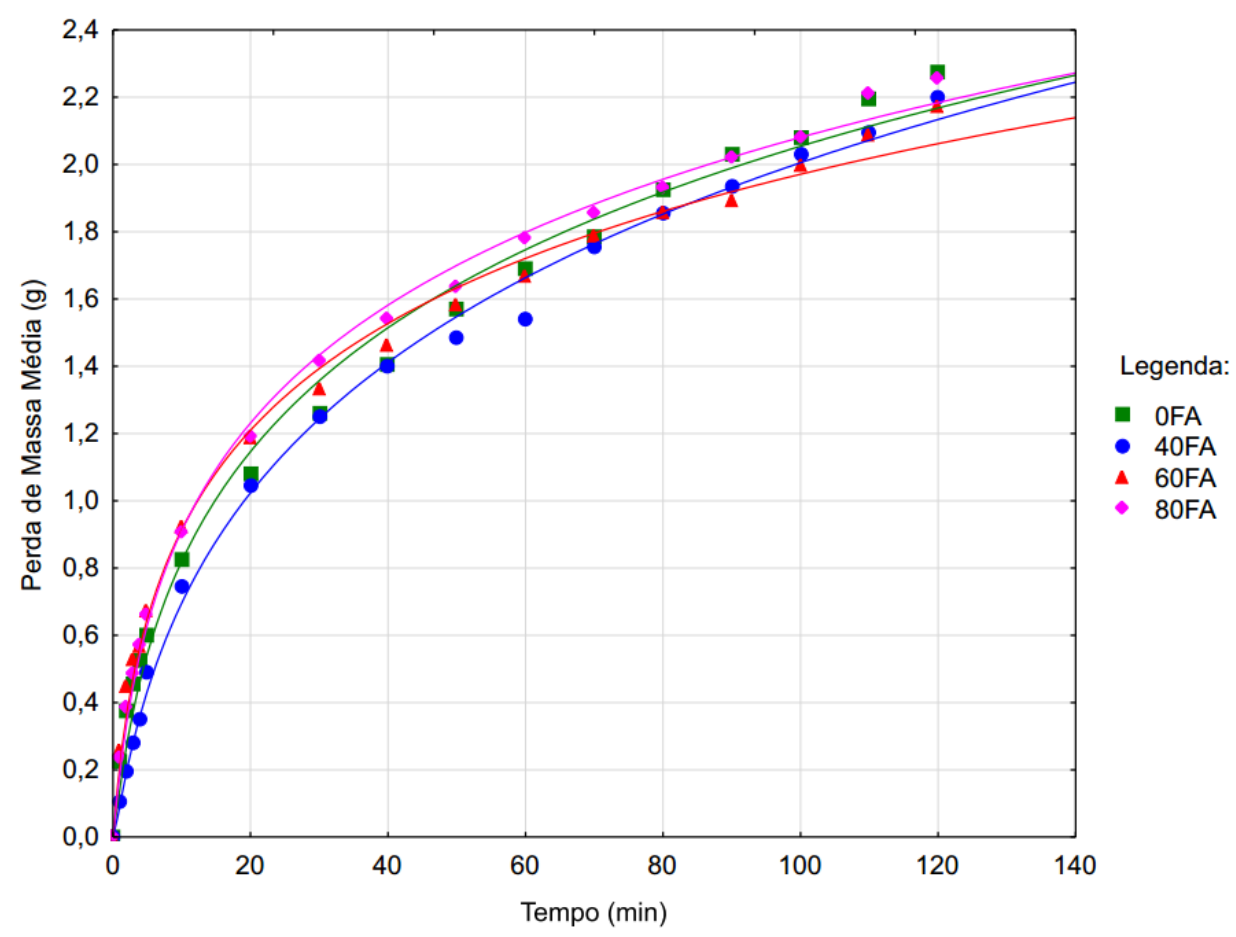

Figura 8: Perdas de massa médias ao longo do tempo de ensaio

Conforme pode ser visto na Figura 8 as curvas não apresentaram grande distinção para as diferentes adições de fibra de aço ao concreto, confirmando o resultado da análise estatística que apontou para a não influencia da adição de fibra na resistência à erosão hidráulica dos concretos.

No estudo realizado por Grolli (2017) acerca da influência da adição de fibra de aço na resistência abrasiva do concreto, foi verificada diminuição da perda de massa do material com o aumento no teor de fibra. O ensaio abrasivo para verificação da resistência à abrasão dos corpos de prova foi realizado conforme a ASTM C1138M (2012), que consiste na circulação de esferas de aço transportadas pela água sobre um corpo de prova de $30 \mathrm{~cm}$ de diâmetro e $10 \mathrm{~cm}$ de altura, durante um período de 72 horas.

Assim sendo, Grolli (2017) observou influência do teor de fibra na resistência abrasiva e constatou que, em todos os casos, a adição de fibra de aço resultou em um ganho na resistência à abrasão hidráulica, mas entre os teores de 40FA e 60FA não houve diferença significativa, já que obtiveram perda de massa estatisticamente igual. Sendo assim, o estudo de Grolli (2017) verificou os benefícios do uso do CRFA em estruturas hidráulicas sujeitas à abrasão, confirmando o verificado por Horszczaruk (2004).

Neste trabalho, o uso de fibras de aço não contribuiu para o aumento da resistência à erosão hidráulica. No entanto, o uso de CRFA em estruturas hidráulicas ainda pode ser interessante, já que as fibras de aço aumentam a resistência à abrasão do concreto e não prejudicam sua resistência à erosão. Por fim os distintos resultados à abrasão e à erosão hidráulica 
atentam, em princípio, a distinção entre erosão e abrasão hidráulica, como indicado inicialmente por Momber e Kovacevic (1994).

\section{CONSIDERAÇOES FINAIS}

Tendo em vista os resultados obtidos por meio da análise estatística dos dados de perda de massa oriundos dos ensaios hidroerosivos em CRFA nos teores de 0FA, 40FA, 60FA e 80FA, conclui-se que a adição de fibra de aço à matriz cimentícia não influencia na perda de massa durante o ensaio erosivo realizado. O modelo matemático de SitnikHorszczaruk (2008) mostrou-se adequado na descrição da perda de massa do material ao longo do tempo, apresentando excelente ajuste aos dados, motivando seu uso em futuros estudos acerca de erosão hidráulica.

Devido ao reforço do concreto com fibras de aço, esperava-se um aumento em sua resistência à erosão, já que no trabalho de Grolli (2017) foi verificado o aumento em sua resistência abrasiva. No entanto, este aumento na resistência abrasiva do material não necessariamente representa um aumento em sua resistência erosiva. Tal resultado indica que é indiferente o uso deste tipo de reforço em situações em que objetiva-se aumento na resistência erosiva de um material, já que para nenhum dos teores utilizados, houve influência do uso de fibras. Entretanto, tal reforço ainda pode ser benéfico em estruturas hidráulicas, já que as fibras de aço aumentam a resistência à abrasão do concreto e não prejudicam sua resistência à erosão.

\section{AGRADECIMENTOS}

As seguintes entidades apoiaram o financiamento e a execução deste trabalho:

- Fundação Parque Tecnológico Itaipu (FPTI);

- Centro de Estudos Avançados em Segurança de Barragens (CEASB);

- ITAIPU Binacional;

- Universidade Estadual do Oeste do Paraná (UNIOESTE).

\section{REFERÊNCIAS}

AMERICAN CONCRETE INSTITUTE. C1138M: Standart Test Method for Abrasion Resistance of Concrete (Underwater Method). 2012.

ASSOCIAÇÃO BRASILEIRA DE NORMAS TÉCNICAS. NBR NM 46: Agregados - Determinação do material fino que passa através da peneira $75 \boldsymbol{\mu m}$, por lavagem. Rio de Janeiro, 2003.

NBR NM 52: Agregado miúdo - Determinação de massa específica e massa específica aparente. Rio de Janeiro, 2003.

. NBR NM 53: Agregado graúdo - Determinação de massa específica, massa específica aparente e absorção de água. Rio de Janeiro, 2003. 1998.

NBR NM 67: Concreto - Determinação da consistência pelo abatimento do tronco de cone. Rio de Janeiro,

.NBR NM 248: Concreto - Agregados - Determinação da composição granulométrica. Rio de Janeiro, 2003.

ASSOCIAÇÃO BRASILEIRA DE NORMAS TÉCNICAS. NBR 5738: Concreto - Procedimento para moldagem e cura de corpos de prova. Rio de Janeiro, 2003.

NBR 5739: Concreto - Ensaio de compressão de corpos de prova cilíndricos. Rio de Janeiro, 1994.

NBR 7211: Agregados para concreto - Especificação. Rio de Janeiro, 2009.

NBR 6118: Projeto de estruturas de concreto - Procedimento. Rio de Janeiro, 2014.

.NBR 8522: Concreto - Determinação dos módulos estáticos de elasticidade e de deformação e da curva tensão-deformação. Rio de Janeiro, 2003. 
CÁNOVAS, M. F. Panorama actual de los hormigones reforzados com fibras de acero. In: CONPAT 97 - IV Congresso Ibero americano de Patologia das Construções e VI Congresso de Controle de Qualidade, 1997, Porto Alegre, Brasil. Anais...Porto Alegre: UFRGS, 1997, p.31-45.

CHIEREGATO, A. C.; GIERRA, E. A.; GOMES, F. M. P.; TRABOUlSI, M. A.; SILVA, R. R.; SANTANA, W. G. Propriedades do CRFA Utilizado na Construção do Vertedouro Extravasor de Troncos da UHE Santo Antônio. In: 58 - Congresso Brasileiro do Concreto, Belo Horizonte. IBRACON, 2016.

FIGUEIREDO, A. D. Capítulo: Concreto com fibras. In: Concreto Projetado: Ensino, Pesquisa e Realizações São Paulo: IBRACON, 2005.

FIGUEIREDO, A. D. Concreto Reforçado com Fibras. São Paulo. 256 p. Tese (Obtenção de título de Livre Docência), Escola Politécnica da Universidade de São Paulo, 2011.

GAVA, G. P. Análise teórica-experimental do comportamento à flexão de vigas de concreto reforçado com fibras de aço. Florianópolis, 2006. 277 p. Tese (Doutorado em Engenharia Civil) - Programa de Pós-Graduação em Engenharia Civil, Universidade Federal de Santa Catarina.

GROLLI, V. Estudo Experimental e Ajustes Numéricos do Desgaste Abrasivo Hidráulico do Concreto Reforçado com Fibras de Aço. 2017. 101p. Trabalho de Conclusão de Curso (Graduação em Engenharia Civil) - Universidade Estadual do Oeste do Paraná, Cascavel, 2017.

HORSZCZARUK, E. Abrasion resistance of high strength fibre reinforced concrete, in: Fibre Reinforced Concretes BEFIB, 2004, RILEM Publications S.A.R.L., vol. 1, Bagneux, 2004, pp. 257-266.

MEHTA, P. K.; MONTEIRO, P. J. M. Concreto: Microestrutura, Propriedades e Materiais. 3. ed. São Paulo: IBRACON, 2008.

MINDESS, S., BANTHIA, N. Fiber Reinforced Cementitious Composites: Current Practice and Future Prospects. v.144, 1994. p. 417-446.

MOMBER, A., KOVACEVIC, R. Fundamental investigations on concrete wear by high velocity water flow. Wear, v. 177, n.1, p. 55-62, 1994.

MOMBER, A. W., KOVACEVIC, R., YE, J. The Fracture of concrete due to Erosive wear by High Velocity Water. Tribology Transactions, v. 38, n.3, p. 686-692, 1995.

NAAMAN, A. E. Fiber reinforcements for concrete: looking back, looking ahead. In: Fibrereinforced concretes (FRC) - BEFIB'2000, 2000, Lyon, France. Proceedings... Edited by P. Rossi and G. Chanvillard, 2000. p. 65-85.

RAMPANELli, C. H. O.; ROHR, N. G.; TRENTINI, C. B.; GAVA, G. P.; RIZZI, R. L. Avaliação do desgaste por erosão hidráulica de materiais para reparo de estruturas de concreto. In: $60^{\circ}$ Congresso Brasileiro do Concreto, 2018, Foz do Iguaçu. $60^{\circ}$ Congresso Brasileiro do Concreto. São Paulo: IBRACON - Instituto Brasileiro do Concreto, 2018.

SARZALEJO, A. G.; ROSSI, B.; PERRI, G.; WINTERBERG, R.; ARISTEGUIETA, R. E. P. Fibras como Elemento Estrutural para Reforço de Concreto. Manual Técnico MACCAFERRI. S. L. 2010.

SITNIK, L. Wear kinetics theory and its potential application to assessment of wear of machine parts. WEAR. v. 265, p. 1038-1045. 2008.

STATSOFT R\&D DEPARTMENT. STATISTICA software version 10. 2300 East 14th St. USA. 2011. 